\title{
Effect of simultaneous oral and vaginal treatment on the rate of cure and relapse in vaginal candidosis
}

\author{
J. D. MILNE AND D. W. WARNOCK \\ From the Bristol Royal Infirmary, Bristol
}

SUMMARY One hundred patients with vulvovaginal candidosis were entered in a double-blind trial to compare the effect of six days' local treatment with clotrimazole with that of the same treatment plus 10 days' oral treatment with nystatin. No significant differences were detected in the rate of cure or relapse between the treatment groups. The cure rate was lowest and the relapse rate highest in patients in whom vaginal candidosis had last been diagnosed during the preceding 12 months.

\section{Introduction}

Vaginal infection with Candida albicans is a common condition (Oriel et al., 1972; Hilton and Warnock, 1975). Most, if not all, patients with this infection also harbour this fungus in their digestive tract (Hilton and Warnock, 1975; Miles et al., 1977), and it has been suggested that the failure of a significant proportion of such patients to respond to local treatment, and the need of others for prolonged or repeated courses of treatment, is due-in part at least - to reinfection from their intestinal tract. Indeed, Miles et al. (1977) suggested that the intestinal reservoir must be eliminated if the genital infection is to be cured.

Oral treatment with nystatin has been shown to reduce intestinal colonisation with $C$. albicans (Seelig, 1968). For this reason, such treatment is often recommended as an adjunct to vaginal treatment in patients with recurrent genital infection (Nicol, 1971; Cartwright, 1978). In fact, it has not been proved that simultaneous treatment of the intestinal tract prolongs freedom from reinfection, and it has not been established that the intestinal tract is recolonised once oral treatment is discontinued. In this investigation we have evaluated the effect of simultaneous oral treatment with nystatin on the rate of cure and relapse in patients presenting with vulvovaginal candidosis.

Address for reprints: $\mathrm{Dr}$ D. W. Warnock, Department of Microbiology, Bristol Royal Infirmary, Marlborough Street, Bristol BS2 8HW

Received for publication 28 March 1979

\section{Patients and methods}

\section{STUDY POPULATION}

The patients studied were 100 non-pregnant women attending the Special Clinic of this hospital. Vaginal candidosis had been diagnosed in 67 of them on at least one previous occasion (on the basis of both clinical and mycological findings), and, at the time of admission to this investigation, all had clinical signs of vulvovaginitis together with a positive result to a vaginal culture (see below). None of the patients had taken antibiotics or received local antifungal treatment during the preceding two weeks.

\section{TREATMENT GROUPS}

Patients were allocated in random order to one of two groups for treatment: those in group 1 were treated with one clotrimazole vaginal pessary $(100 \mathrm{mg})$ daily for six consecutive days plus one oral nystatin tablet four times daily for 10 consecutive days; and those in group 2 were treated with one clotrimazole vaginal pessary daily for six days plus one identical oral placebo tablet four times daily for 10 days. The composition of the two groups of patients was similar (Table 1).

\section{FOLLOW-UP ASSESSMENT}

All patients were requested to return for assessment at two, four, and eight weeks after treatment was begun. On each occasion symptoms and clinical signs of vaginitis (the vaginal mucosa was reddened or granular), vulvitis (the vulva was reddened, swollen, fissured, or ulcerated), and discharge were noted. High vaginal swabs were taken at each visit, placed in transport medium (Oxoid Trichomonas Medium No. 2 ), and sent for mycological investigation. The 
Table 1 Characteristics of the 100 patients studied

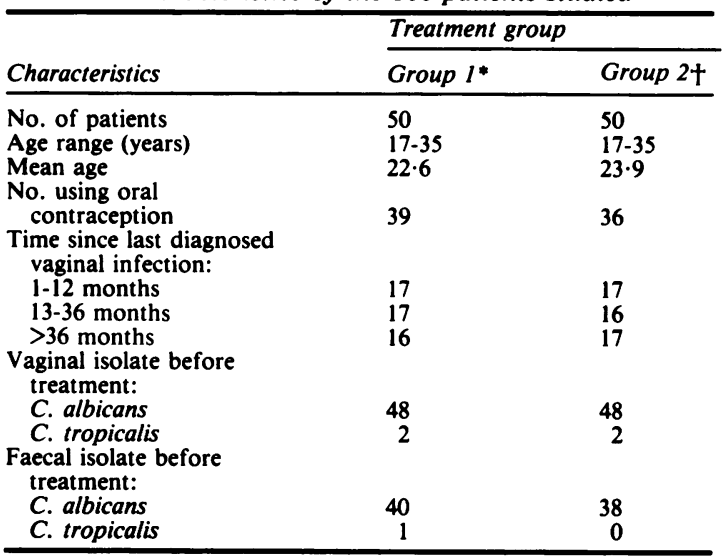

* Group treated with clotrimazole vaginal pessary plus oral nystatin + Group treated with pessary alone

patients also provided a faecal specimen on each occasion. Clinical observations were all made by one observer.

Vaginal and faecal specimens were inoculated on to plates of glucose peptone agar containing $0.05 \mathrm{mg}$ chloramphenicol per $\mathrm{ml}$ and incubated at $37^{\circ} \mathrm{C}$ for 48 hours. Identification of isolates was based on morphological and biochemical tests according to English (1974).

\section{STATISTICAL METHOD}

The results were analysed with the $\chi^{2}$ test (with Yates's correction).

\section{Results}

The patients were assessed two weeks after treatment was begun and the findings are summarised in Table 2. In this Table, the patients have been classified as follows: clinical and mycological cure means no clinical signs of infection and a negative vaginal culture result; mycological failure means no clinical signs of infection and a positive vaginal culture

Table 2 Effect of treatment on 100 patients assessed at two weeks

\begin{tabular}{lllll}
\hline & \multicolumn{4}{c}{ No. of patients } \\
\cline { 3 - 5 } $\begin{array}{l}\text { Treatment } \\
\text { group }\end{array}$ & $\begin{array}{l}\text { Time since } \\
\text { last diagnosed } \\
\text { infection }\end{array}$ & $\begin{array}{l}\text { Clinical and } \\
\text { mycological } \\
\text { cure }\end{array}$ & $\begin{array}{l}\text { Mycological } \\
\text { failure }\end{array}$ & $\begin{array}{l}\text { Clinical and } \\
\text { mycological } \\
\text { failure }\end{array}$ \\
\hline Group 1* $1^{*}$ & $1-12$ months & 12 & 3 & 2 \\
& $13-36$ months & 15 & 1 & 1 \\
Group 2+ & $>36$ months & 15 & 1 & 0 \\
& $1-12$ months & 11 & 3 & 3 \\
& $13-36$ months & 14 & 1 & 1 \\
& $>36$ months & 14 & 2 & 1 \\
\hline
\end{tabular}

* Group treated with clotrimazole vaginal pessary plus oral nystatin + Group treated with pessary alone result; clinical and mycological failure means clinical signs of infection and a positive vaginal culture result.

The patients in each treatment group were subdivided into three subgroups: (a) those in whom vaginal candidosis had been diagnosed during the preceding 12 months; (b) those in whom the condition had last been diagnosed during the preceding 13 to 36 months; (c) and those in whom the condition had not been diagnosed during the preceding 36 months.

The cure rate was lowest, and the failure rate highest, in the group of patients in whom vaginal candidosis had been diagnosed during the preceding 12 months. No significant differences could be detected in the cure rate or failure rate between the treatment groups.

\section{VAGINAL CULTURES}

The results of vaginal cultures performed at two, four, and eight weeks are presented in Table 3 as the number of patients with positive culture results seen on each occasion. Not all the patients returned at four or eight weeks; 12 patients with negative vaginal culture results at two weeks failed to attend at four or eight weeks and 20 patients with negative vaginal culture results at four weeks failed to return at eight weeks.

At two weeks, eight patients in group 1 (those treated with clotrimazole pessary plus oral nystatin) and 11 patients in group 2 (those treated with pessary alone) still had positive vaginal culture results (Table 3). Thirteen of these patients required further treatment. Up to eight weeks a further nine patients in group 1 had become reinfected; four of these patients had returned with symptoms and clinical signs of infection and had needed further treatment. Seven patients in group 2 who had returned at four or eight weeks had become reinfected; three of these patients required further treatment. No significant difference in the reinfection rate was detected between the two treatment groups at four or eight weeks.

\section{FAECAL CULTURES}

The number of patients in each treatment group with positive faecal culture results before treatment and at two, four and eight weeks is presented in Table 4. In all, 79 patients had positive faecal culture results before treatment; 20 patients in group 1 and 24 patients in group 2 had positive faecal culture results before treatment and again two weeks later. No significant differences were detected between the two treatment groups before treatment or at two, four, or eight weeks. 
Table 3 Number of patients with positive vaginal culture results at two, four, and eight weeks

\begin{tabular}{|c|c|c|c|c|}
\hline \multirow[b]{2}{*}{$\begin{array}{l}\text { Treatment } \\
\text { group }\end{array}$} & \multirow{2}{*}{$\begin{array}{l}\text { Time since last } \\
\text { diagnosed } \\
\text { infection }\end{array}$} & \multicolumn{3}{|c|}{ No. of patients with positive results at (weeks) } \\
\hline & & 2 & 4 & 8 \\
\hline Group $2 \ddagger$ & $\begin{array}{l}\text { 1-12 months } \\
13-36 \text { months } \\
>36 \text { months } \\
\text { 1-12 months } \\
13-36 \text { months } \\
>36 \text { months }\end{array}$ & $\begin{array}{l}5(4)^{*} \\
2(2) \\
1(0) \\
6(3) \\
2(1) \\
3(3)\end{array}$ & $\begin{array}{l}2(1) \\
3(1) \\
3(1) \\
1(1) \\
1(0) \\
1(0)\end{array}$ & $\begin{array}{l}0 \\
1(1) \\
0 \\
0 \\
2(2) \\
2(0)\end{array}$ \\
\hline
\end{tabular}

* Numbers in parentheses indicate no. of patients with clinical signs of infection requiring further treatment

+ Group treated with clotrimazole vaginal pessary plus oral nystatin

₹ Group treated with pessary alone

Table 4 Number of patients with positive faecal culture results before treatment and at two, four, and eight weeks

\begin{tabular}{|c|c|c|c|c|c|}
\hline \multirow[b]{2}{*}{ Treatment group } & \multicolumn{2}{|l|}{ Before treatment } & \multicolumn{3}{|c|}{ Cumulative no. of patients with positive results at (weeks) } \\
\hline & Faecal culture result & No. of patients & 2 & 4 & 8 \\
\hline $\begin{array}{l}\text { Group 1* } \\
\text { Group 2† }\end{array}$ & $\begin{array}{l}\text { Positive } \\
\text { Negative } \\
\text { Positive } \\
\text { Negative }\end{array}$ & $\begin{array}{r}41 \\
9 \\
38 \\
12\end{array}$ & $\begin{array}{r}20 \\
0 \\
24 \\
2\end{array}$ & $\begin{array}{r}25 \\
3 \\
29 \\
3\end{array}$ & $\begin{array}{r}27 \\
3 \\
29 \\
3\end{array}$ \\
\hline
\end{tabular}

* Group treated with clotrimazole vaginal pessary plus oral nystatin

+ Group treated with pessary alone

Table 5 Faecal findings in 35 patients with positive vaginal culture results at two, four, or eight weeks

\begin{tabular}{|c|c|c|c|c|c|c|c|c|c|c|}
\hline \multirow[b]{4}{*}{ Treatment group } & \multicolumn{10}{|l|}{ Culture results } \\
\hline & \multirow{3}{*}{$\begin{array}{l}\text { Before treatment } \\
\text { Faecal }\end{array}$} & \multicolumn{3}{|c|}{ At 2 weeks } & \multicolumn{3}{|c|}{ At 4 weeks } & \multicolumn{3}{|c|}{ At 8 weeks } \\
\hline & & \multicolumn{2}{|c|}{ Faecal } & \multirow{2}{*}{$\frac{\text { Vaginal }}{+}$} & \multicolumn{2}{|c|}{ Faecal } & \multirow{2}{*}{$\frac{\text { Vaginal }}{+}$} & \multicolumn{2}{|c|}{ Faecal } & \multirow{2}{*}{$\frac{\text { Vaginal }}{+}$} \\
\hline & & + & - & & + & - & & + & - & \\
\hline $\begin{array}{l}\text { Group 1* } \\
\text { Group 2† } \\
\text { Total }\end{array}$ & $\begin{array}{l}\text { Positive } \\
\text { Negative } \\
\text { Positive } \\
\text { Negative }\end{array}$ & $\begin{array}{l}2 \\
0 \\
5 \\
1 \\
8\end{array}$ & $\begin{array}{r}4 \\
2 \\
3 \\
2 \\
11\end{array}$ & $\begin{array}{l}11 \\
19\end{array}$ & $\begin{array}{l}6 \\
0 \\
2 \\
0 \\
8\end{array}$ & $\left.\begin{array}{l}0 \\
2 \\
1 \\
0 \\
3\end{array}\right\}$ & $\begin{array}{l}3 \\
11\end{array}$ & $\begin{array}{l}1 \\
0 \\
2 \\
0 \\
3\end{array}$ & $\left.\begin{array}{l}0 \\
0 \\
1 \\
1 \\
2\end{array}\right\}$ & $\begin{array}{l}4 \\
5\end{array}$ \\
\hline
\end{tabular}

+ Positive - negative

* Gosoup treated with clotrimazole vaginal pessary plus oral nystatin

† Group treated with pessary alone

The mycological findings in the 35 patients with positive vaginal culture results at two, four, or eight weeks are summarised in Table 5. Eleven of the 19 patients with positive vaginal culture results at two weeks had negative faecal culture results. Seven of the nine patients in group 1 with positive vaginal culture results at four or eight weeks also had positive faecal culture results. Two patients in this group had negative faecal culture results on both occasions. Four of the seven patients in group 2 with positive vaginal culture results at four or eight weeks also had positive faecal culture results.

\section{Discussion}

Many clinicians consider simultaneous oral treatment with nystatin to be a useful adjunct to the local treatment of patients with persistent vulvovaginal candidosis on the assumption that such treatment will help to prevent reinfection from the intestinal tract. Most of the patients admitted to this investigation had positive faecal culture results as did most of the patients who became reinfected. In this respect, our findings confirm those of another recent investigation (Miles et al., 1977).

Our findings indicate that simultaneous oral and vaginal treatment did not bring about a higher cure rate. This is in accordance with the findings of Velupillai and Thin (1977), who detected no significant difference between the effect of combined local and oral nystatin treatment compared with local nystatin treatment alone. The oral treatment regimen adopted in this investigation has been recommended for the treatment of patients with long-standing 
vaginal candidosis (Nicol, 1971; Cartwright, 1978), but it failed to eradicate faecal colonisation in a substantial proportion of our patients. It is interesting that the number of patients with positive faecal culture results in the group treated with pessary alone decreased during treatment. The reason for this apparent loss of intestinal colonisation is uncertain but the antifungal preparation may have contaminated the anal tract and so reduced or eliminated faecal colonisation.

It cannot be said for certain that the patients who responded to treatment but later relapsed derived their later infection from their intestinal tract. Eight of the 11 patients with positive vaginal culture results at four weeks and three of the five patients with positive vaginal culture results at eight weeks did have positive faecal culture results. This does suggest that the intestinal tract may be a source of vaginal infection, but other sources of infection, including the male partner (Rodin and Kolator, 1976), cannot be discounted.

In conclusion, simultaneous oral treatment with nystatin did not increase the cure rate nor did it decrease the relapse rate in our patients. Prolonged oral treatment with nystatin has helped a number of patients with chronic vulvovaginal candidosis, but this investigation has shown that intestinal colonisation often recurs once oral treatment has been discontinued. If the mouth is the principal source of intestinal colonisation, then eradication of this reservoir of infection might help to reduce the spread of $C$. albicans. Intermittent prophylactic treatment could be the best means of preventing vulvovaginal infection in predisposed patients. The beneficial effect of intermittent vaginal treatment has been reported (Davidson and Mould, 1978), but the role of intermittent intestinal treatment remains to be evaluated.

The authors are indebted to the late $\operatorname{Dr} \mathrm{A}$. L. Hilton and Dr C. S. Good for their help in the design of this investigation, to the staff of the Special Clinic for their co-operation, and to Bayer UK Limited for financial support.

\section{References}

Cartwright, R. Y. (1978). Use of antibiotics. Antifungals. British Medical Journal, 2, 108-111.

Davidson, F. and Mould, R. F. (1978). Recurrent genital candidosis in women and the effect of intermittent prophylactic treatment. British Journal of Venereal Diseases, 54, 176-183.

English, M. P. (1974). Identifying yeasts. Medical Laboratory Technology, 31, 327-333.

Hilton, A. L. and Warnock, D. W. (1975). Vaginal candidiasis and the role of the digestive tract as a source of infection. British Journal of Obstetrics and Gynaecology, 82, 922-926.

Miles, M. R., Olsen, L., and Rogers, A. (1977). Recurrent vaginal candidiasis. Importance of an intestinal reservoir. Journal of the American Medical Association, 238, 1836-1837.

Nicol, C. S. (1971). Other sexually transmitted diseases II. British Medical Journal, 2, 507-509.

Oriel, J. D., Partridge, B. M., Denny, M. J., and Coleman, J. C. (1972). Genital yeast infections. British Medical Journal, 4, 761-764.

Rodin, P. and Kolator, B. (1976). Carriage of yeasts on the penis. British Medical Journal, 1, 1123-1124.

Seelig, M. S. (1968). The rationale for preventing antibacterialinduced fungal overgrowth. Medical Times, 96, 689-712.

Velupillai, S. and Thin, R. N. (1977). Treatment of vulvovaginal yeast infection with nystatin. Practitioner, 219, 897-901. 